\title{
Prolina livre em alecrim-pimenta sob estresse hídrico antes da colheita
}

\author{
ALVARENGA, I.C.A. ${ }^{1 *}$; QUEIROZ, G.A. ${ }^{2}$; HONÓRIO, I.C.G ${ }^{3}$.; VALADARES, R.V. ${ }^{2}$; MARTINS, E. R. \\ ${ }^{2}$ Departamento de Agricultura Geral, Universidade Federal de Lavras. Cx. Postal 37, CEP 37200-000, Lavras, \\ Brasil *pytchouai@yahoo.com.br. ${ }^{2}$ Instituto de Ciências Agrárias, Universidade Federal de Minas Gerais, ICA/ \\ UFMG, CEP 39404-006, Montes Claros-Brasil. ${ }^{3}$ Universidade Federal de Viçosa CEP 36570-000, Viçosa-Brasil.
}

\begin{abstract}
RESUMO: O estresse hídrico é considerado um dos fatores limitantes para o desenvolvimento das plantas, com isso, os vegetais desenvolvem mecanismos para tolerar a deficiência hídrica do solo. Entre esses mecanismos, está o acúmulo de prolina livre nos tecidos, tendo como função a regulação osmótica dos tecidos. A influência do estresse hídrico em plantas medicinais ainda é pouco estudado, principalmente em plantas nativas, como é o caso do alecrim-pimenta Lippia sidoides Cham. Assim, o trabalho teve por objetivo avaliar a prolina livre e o teor de flavonoides totais na referida espécie sob condições de estresse hídrico antes da colheita. O trabalho foi realizado no Instituto de Ciências Agrárias da UFMG, Campus Montes Claros, delineamento em blocos casualizados, com 5 tratamentos e 4 repetições, sendo eles 8, 6, 4, 2 e 0 dias de supressão da irrigação antes da colheita. Os teores encontrados de prolina variaram entre 0,2489 a 3,2421 ì.g $\mathrm{g}^{-1}$ de matéria seca e de flavonoides entre 0,0139 a 0,008 g. $\mathrm{g}^{-1}$. Os resultados observados indicam que a planta diminui seu teor de flavonoides e aumenta o teor de prolina com o aumento do período de estresse.
\end{abstract}

Palavras chave: Lippia sidoides Cham., prolina, flavonoides totais, estresse hídrico.

ABSTRACT: Free proline in Lippia sidoides Cham. under water stress before harvest. Water stress is considered a limiting factor for plant growth, thus, the plants develop mechanisms to tolerate the soil water deficit. Among these mechanisms is the accumulation of free proline in tissues, with the poke the osmotic regulation of tissues. The influence of water stress in medicinal plants is still poorly studied, mainly on native plants such as rosemary-pepper Lippia sidoides Cham. Thus, the study aimed to evaluate the free proline and total flavonoid content in that species under conditions of water stress before harvest. The study was conducted at the Institute of Agricultural Sciences, UFMG, Campus Montes Claros, randomized block design with 5 treatments and 4 replicates, and they 8, 6, 4, 2 and 0 days of withholding irrigation before harvest. The content of proline ranged from 0.2489 to $3.2421 \mathrm{iM} . \mathrm{g}-1$ of dry matter and flavonoids from 0.0139 to $0.008 \mathrm{gg}-1$. The results indicate that the plant reduces its content of flavonoids and proline content increases with increasing stress time.

Key words: Lippia sidoides Cham., proline, flavonoids, water stress.

\section{INTRODUÇÃO}

O estresse por deficiência hídrica ocorre quando pouca água está disponível em um estado termodinâmico apropriado. Essa situação pode ocorrer por uma série de razões, tais como, excesso de evaporação, água ligada osmoticamente aos solos salinos, ou ainda, devido ao congelamento nos solos. As plantas têm mecanismos bioquímicos desenvolvidos para lidar com a falta de água, os processos desencadeados pela seca e a adaptação à alta disponibilidade de água em períodos curtos são bastante desiguais, sendo que cada célula tem mais de um mecanismo para reagir à seca, e tem por assim dizer, uma rede de segurança múltipla (Schulze et al., 2005).

Entre as alterações metabólicas, temos o acúmulo de prolina, que ocorre não advindo somente do déficit hídrico, mas também salinidade, altas ou baixas temperaturas, toxicidade a metais pesados, deficiência nutricional, entre outros, acredita-se que a prolina atue no ajustamento osmótico, estabilização de estruturas subcelulares e na eliminação de radicais livres, ou ainda participar na constituição de um

Recebido para publicação: agosto de 2011

Aceito para publicação: dezembro de 2011

Rev. Bras. PI. Med., Botucatu, v.13, especial, p.539-541, 2011. 
estoque de $\mathrm{N}$ e $\mathrm{C}$ que poderia ser utilizado depois do período de estresse, (Leite et al., 2000; Taylor, 1996).

O nível e a duração do estresse são fundamentais na resposta das plantas aromáticas e medicinais, assim, estudos têm indicado que plantas de qualidade podem ser obtidas por meio de sistemas de reduzida irrigação (Charles et al., 1990; Morvant et al.,1998). Os estudos avaliando o comportamento de plantas medicinais demonstram significativa influência do déficit hídrico tanto na produção como na formação de compostos tais como partenolíticos, flavonoides, óleos essenciais e alcaloides, (Penka, 1978, Carvalho et al., 2003, Castro et al., 2004, Bortolo et al., 2009).

O alecrim-pimenta (Lippia sidoides Cham.) é uma espécie aromática e medicinal, nativa, originária do Nordeste brasileiro e de regiões semi-áridas do Norte de Minas Gerais, sendo utilizada na medicina popular no tratamento de micoses, inflamações bucais, escabiose e maus odores corporais. Seu óleo essencial, composto por uma mistura de timol e carvacrol entre outros compostos voláteis é responsável pelas propriedades antimicrobianas contra fungos, bactérias e atividade anti-helmíntica em parasitas de ovinos. Os estudos sobre o cultivo irrigado do alecrim-pimenta são incipientes, não se conhecendo o comportamento da planta frente a condições de estresse (ALVARENGA, et al., 2009). Assim, o presente trabalho objetivou avaliar 0 comportamento do alecrim-pimenta em condições de estresse hídrico antes da colheita, por meio da avaliação da prolina livre e teor de flavonoides totais.

\section{MATERIAL E MÉTODO}

O experimento foi instalado na área experimental do Instituto de Ciências Agrárias (ICA) da Universidade Federal de Minas Gerais (UFMG) situado no município de Montes Claros-MG, cujas coordenadas são $16^{\circ} 44^{\prime} 02.8^{\prime \prime}$ de latitude $S$ e $43^{\circ} 51^{\prime}$ 23.3"de longitude W e altitude de $646 \mathrm{~m}$. O clima é denominado Aw-clima tropical de savana com inverno seco e verão chuvoso, semi-árido, segundo a classificação de Köeppen (Leite et al., 2004).

O trabalho foi conduzido em lisímetros de drenagem, onde o solo de cultivo foi classificado como Latossolo Vermelho-Amarelo, de textura argilosa. $O$ período de cultivo ocorreu no período de 15 de setembro de 2009 a 11 de junho de 2010 , totalizando 270 dias de cultivo. As plantas foram oriundas de rebrota de plantas colhidas com 120 dias de transplantio, sendo que as mudas foram produzidas com material propagativo do Horto de Plantas Medicinais da presente instituição.

Os tratamentos consistiram na supressão de irrigação por cinco períodos, ou seja, 8 (T5), 6 (T4), 4 (T3), 2 (T2) e 0 (T1) dias antes da colheita, perfazendo cinco tratamentos no delineamento inteiramente casualizado, com quatro repetições. Aos 95 dias de cultivo foi feita uma adubação suplementar com esterco bovino curtido com $12 \mathrm{~kg} \mathrm{~m}^{-2}$ (Assis et al. 2009). A irrigação era realizada com base na Evapotranspiração de referência (ETo) calculada conforme a equação Hargreaves-Samani (Pereira et al., 1997). Os dados meteorológicos para a determinação da ETo foram coletados na estação meteorológica automática Davis, modelo Vantage Pro 2, presente na área experimental. A extração de prolina foi realizada a partir de $300 \mathrm{mg}$ de amostra de folhas frescas homogeneizadas em $10 \mathrm{ml}$ de ácido sulfosalicílico a $3 \%$ por cerca de 2 minutos. A estimativa do teor de prolina foi feita segundo método colorimétrico de Bates et al. (1973). A avaliação dos teores de flavonoides totais foi determinada a partir da adaptação da metodologia de Santos e Blatt (1997). Os dados foram submetidos ao teste Tukey a $5 \%$ de probabilidade para comparação das medias.

\section{RESULTADO E DISCUSSÃO}

$O$ teor de prolina livre variou entre $0,2489 \mathrm{e}$ 3,2421 ì. i $^{-1}$ de matéria seca, observando-se 0 incremento do metabólito conforme o aumento do período de estresse hídrico, havendo diferença significativa entre os tratamentos, sendo que aos 8 dias de estresse, o teor de prolina foi de aproximadamente 13 vezes superior ao tratamento controle (Tabela 1). Isso é um possível indicativo de adaptação da planta ao estresse hídrico. Carvalho et al., 2005, avaliando o crescimento de Tanacetum parthenium sob diferentes condições de umidade do substrato, encontrou valores de prolina livre variando entre 9 e 32ìg. $\mathrm{g}^{-1}$, respectivamente para o tratamento de menor e maior estresse, relativo a capacidade de campo do solo, indicando a planta como acumuladora de prolina sob condições de estresse. Em alecrimpimenta os teores foram relativamente baixos devido ao pequeno período de estresse.

Os teores de flavonoides apresentaram comportamento decrescente acompanhando o tempo de déficit hídrico nas plantas, sendo que os teores observados variaram de 0,0139 a $0,008 \mathrm{~g} \cdot \mathrm{g}^{-1} \mathrm{de}$ flavonóides na matéria seca, não diferindo estatisticamente entre os tratamentos (Tabela 1).

Esse comportamento indica que a produção de flavonoides é sensível ao déficit hídrico para a planta, contrastando com o trabalho de Bortolo et al. (2009), que avaliaram a concentração de flavonoides nas flores e em plantas de calêndula (Calendula officinallis), aplicando diferentes lâminas de irrigação, não tendo observado diferença significativa do metabólito nas flores. Porém, nas plantas, o teor de flavonoides decresceu com o aumento de lâmina de irrigação, apresentando resposta linear negativa,

Rev. Bras. PI. Med., Botucatu, v.13, especial, p.539-541, 2011. 
TABELA 1. Teores de prolina livre e flavonoides totais em Lippia sidoides Cham. sob estresse hídrico antes da colheita Montes Claros, MG, 2010.

\begin{tabular}{ccc}
\hline $\begin{array}{c}\text { Tratamentos } \\
\text { (dias de estresse) }\end{array}$ & Prolina livre $\left(\mu \mathrm{M} \cdot \mathrm{g}^{-1}\right)$ & Flavonoides $\left(\mathrm{g} \cdot \mathrm{g}^{-1}\right)$ \\
\hline 0 & $0,2489 \mathrm{~b}$ & $0,0139^{\mathrm{ns}}$ \\
\hline 2 & $0,6468 \mathrm{~b}$ & 0,0130 \\
\hline 4 & $0,7011 \mathrm{~b}$ & 0,0096 \\
\hline 6 & $1,1623 \mathrm{~b}$ & 0,0081 \\
\hline 8 & $3,2421^{*} \mathrm{a}$ & 0,0079 \\
\hline
\end{tabular}

*As médias seguidas pela mesma letra na coluna não se diferenciam estatísticamente entre si pelo teste

Tukey a $5 \%$ de probabilidade; ns- não significativo.

sendo o maior valor $\left(0,072 \mathrm{~g}_{\text {planta- }}{ }^{-1}\right)$ obtido para o tratamento sem irrigação e o menor (0,0019 g planta1) para a maior lâmina. Assim, nas condições de condução do experimento, pode-se inferir que o estresse hídrico antes da colheita em Lippia sidoides Cham. provoca o acúmulo de prolina livre e decréscimo no teor de flavonoides.

\section{AGRADECIMENTO}

Os autores agradecem ao Fundo de Amparo a pesquisa de Minas Gerais (FAPEMIG), ao Conselho Nacional de Desenvolvimento Científico e Tecnológico (CNPq) o financiamento do trabalho e ao PETAGRONOMIA-UFMG.

\section{REFERÊNCIA}

ALVARENGA, I.C.A. et al. Alecrim-pimenta (Lippia sidoides Cham.): uma espécie aromática e medicinal em domesticação. Caderno de Ciências Agrárias, Montes Claros, v. 1. n. 43, p. 9-25, 2009.

ASSIS, B. F. et al. Produção de fitomassa e de óleo essencial de alecrim-pimenta em função da adubação orgânica. Curitiba. Revista Brasileira de Agroecologia Maringá, v. 4, n. 2, p. 4385-4388, nov. 2009.

BATES, L.S.; WALDREN, R.P.; TEARE, J.D. Rapid determination of free proline for water-stress studies. Plant and Soil, v. 39, p. 205-207, 1973.

BORTOLO, D. P. G.; MARQUES, P. A. A.; PACHECO, A. C. Teor e rendimento de flavonóides em calêndula (Calendula officinalis L.) cultivada com diferentes lâminas de irrigação. Revista Brasileira de Plantas
Medicinais, Botucatu, v. 11, n. 4, p. 435-441, 2009. CARVALHO, L. M.; CASALI, V. W. D.; SOUZA, M. A. Soil water availability and growth of feverfew. Horticultura Brasileira, Brasília, DF, v. 21, n. 4, p. 726-730, 2003. CASTRO, H. G. et al. Contribuição ao estudo das plantas medicinais: metabólitos secundários. Viçosa: UFV, 2004. 113 p.

CHARLES, D.J.; JOLY, R.J.; SIMON, J. E. Effects of osmotic stress on the essential oil content and composition of peppermint. Phytochemistry, Oxford. v. 29, n. 9, p. 28372840, 1990.

LEITE, G. L. D.et al. Intensidade de ataque de tripes, de alternaria e da queima-das-pontas em cultivares de cebola. Horticultura Brasileira, Brasília, v. 22, n. 1, p. 151-153, 2004.

LEITE, M.L. et al. Variação de prolina em folhas de caupi (Vigna unguiculata (L.) Walp) submetido a diferentes défcits hídricos. Revista Biotemas, v.12, n.1 p.21-33. 2000.

MORVANT, J. K.; DOLE, J. M.; COLE, J. C. Irrigation frequency and system affect Poinsettia growth, water use, and runoff. Hort Science, Alexandria, v. 33, p. 42-46, 1998.

PENKA, M. Influence of irrigation on the contentents of effetctive substances in officinal plants. Acta Horticulturae, Leuven, v. 7, n. 3, p. 181-198, 1978. PEREIRA, A. R.; NOVA, N. A. V.; SEDIYAMA, G. C. Evapo(transpi)ração. Piracicaba: FEALQ, 1997. 183 p. SANTOS, M. D.; BLATT, C. T. T.; Teor de flavonoides e fenóis totais em folhas de Pyrostegia venusta Miers. de mata e de Cerrado. Revista Brasileira de Botânica, São Paulo, v. 21, p. 1-9, 1998.

SCHULZE, E. D., BECK, E.; MULLER-HOHENSTEIN, K. Plant ecology. Berlin: Springer, 2005.

TAYLOR, C. B. Proline and water deficit: ups, downs, ins, and outs. Plant Cell, Rockville, v. 8, p. 1221-1224, 1996. 